\title{
A Set of Genes Differentially Expressed Between Avirulent and Virulent Meloidogyne incognita Near-Isogenic Lines Encode Secreted Proteins
}

\author{
Cédric Neveu, Stéphanie Jaubert, Pierre Abad, and Philippe Castagnone-Sereno \\ INRA, Unité Interactions Plantes-Microorganismes et Santé Végétale, BP 2078, 06606 Antibes cedex France
}

Submitted 26 February 2003. Accepted 9 July 2003.

\begin{abstract}
A cDNA-amplification fragment length polymorphism (AFLP)-based strategy has been used to identify genes differentially expressed between two pairs of near-isogenic lines (NIL) of the root-knot nematode Meloidogyne incognita either avirulent or virulent against the tomato $M i$ resistance gene. Gene expression profiles from infective secondstage juveniles $(\mathrm{J} 2)$ were compared, and 22 of the 24,025 transcript-derived fragments (TDF) generated proved to be differential, i.e., present in both avirulent NIL and absent in both virulent NIL. Fourteen of the TDF sequences did not show any significant similarity to known proteins, while eight matched reported sequences from nematodes and other invertebrates. The differential expression of nine genes was confirmed by reverse transcription-polymerase chain reaction (RT-PCR) experiments. In situ hybridization conducted with five of the sequences showed that two were specifically expressed in the intestinal cells (HM10 and PM1), one in the subventral esophageal glands (HM1), and two in the dorsal esophageal gland of J2 (HM7 and HM12). Analysis of full-length cDNA sequences revealed the presence of a signal peptide for HM1, HM10, and HM12, indicating that the encoded proteins are putatively secreted. Since secreted products in general and esophageal gland secretions in particular are thought to be among the main $M$. incognita pathogenicity factors, this result suggests a possible dual role for some of the genes encoding such secretions, i.e., they could be involved in both pathogenicity and virulence or avirulence of these biotrophic parasites.
\end{abstract}

Additional keywords: mitotic parthenogenesis, plant-parasitic nematode, selection.

Due to the current restrictions in the use of chemical nematicides, host resistance is being considered as the most efficient method to control plant-parasitic nematodes. Plants are defined as resistant when they block the nematode life cycle, thus reducing or suppressing its reproduction, and resistance has been used successfully in a number of diverse crops (Trudgill 1991; Williamson and Hussey 1996). Resistance genes against rootknot nematodes from the genus Meloidogyne, which constitute a leading cause of crop losses due to plant-parasitic nematodes,

Corresponding author: P. Castagnone-Sereno; Fax: +33 493678955; Email: pca@antibes.inra.fr

Nucleotide sequence data reported are available in the EMBL/GenBank/ DDBJ databases under the accession numbers listed in Table 1. have been identified in many plant species (Roberts 1995). In particular, the tomato $M i$ gene, which confers effective resistance to the three major root-knot nematode species $M$. arenaria, $M$. incognita, and $M$. javanica, is, so far, one of the best characterized nematode resistance genes (Williamson 1998). Resistance was identified in the wild tomato species $L y$ copersicon peruvianum, and a single, interspecific hybrid plant was produced with the cultivated tomato $L$. esculentum using embryo rescue (Smith 1944). Up to now, all the available tomato cultivars with resistance to Meloidogyne spp. originated from this hybrid plant. The expression of $M i$-mediated resistance is characterized by a localized hypersensitive reaction that consists of plant cell necrosis at the nematode infection site (Williamson and Hussey 1996). The Mi gene was isolated by positional cloning and shown to belong to the leucine zipper, nucleotide binding, leucine-rich repeat family of plant resistance genes (Milligan et al. 1998).

Although satisfactory from a conceptual point of view, plant resistance may lose its practical utility when resistant cultivars are challenged with virulent nematode populations. For example, natural Meloidogyne biotypes virulent against the tomato $\mathrm{Mi}$ gene have been described from a number of recent reports (Eddaoudi et al. 1997; Ornat et al. 2001). So far, the molecular mechanisms involved in virulence or avirulence to plant resistance genes are largely unknown in nematodes. In a previous study, in order to identify markers correlated with virulence or avirulence, we assembled a collection of natural root-knot nematode isolates either avirulent or virulent against the $M i$ gene and assessed their molecular diversity by amplification fragment length polymorphism (AFLP) analysis. However, no correlation was found between virulence phenotypes and DNA markers, which suggested that genetic polymorphism was independent of virulence (Semblat et al. 2000). This result also indicated that another strategy needed to be developed to isolate genes involved in virulence or avirulence in root-knot nematodes. Although reproduction in the major species occurs by mitotic parthenogenesis (Triantaphyllou 1985), the selection of $M i$-virulent lines from progenies of single avirulent nematodes was demonstrated for $M$. incognita under laboratory conditions (Bost and Triantaphyllou 1982; Jarquin-Barberena et al. 1991). In such conditions, the avirulent and virulent lines should theoretically be nearly isogenic, just differing in their ability to overcome the resistance gene. Therefore, it can be hypothesized that any molecular difference between them is related to the character of interest, and thus, such near-isogenic lines (NIL) constitute an ideal starting point for the identification of virulence or avirulence genes by means of differential analysis. Recently, a cDNA encoding an amphid-secreted putative avirulence protein from $M$. incognita was cloned through 
the genomic fingerprinting of three pairs of such NIL (Semblat et al. 2001). The similarity of the fingerprints validated the near-isogenicity of these genotypes and their utility for the development of a differential cloning strategy.

The goal of the present study was the identification of genes that are differentially regulated in avirulent and virulent nematodes, in order to understand the molecular basis of $M$. incognita virulence or avirulence in response to the selective pressure of the tomato $M i$ resistance gene. For that purpose, we have used a previously established model system involving selection of pairs of NIL originating from isolates from very different geographic origins (Jarquin-Barberena et al. 1991; Semblat et al. 2001), with the objective to find genes whose regulation would be the same in both avirulent lines and different from both virulent lines. Since cDNA-AFLP (Bachem et al. 1996) has often been described as an extremely efficient method for isolation of genes differentially expressed in plantmicrobe interactions (Durrant et al. 2000; Qin et al. 2000; Simoes-Araujo et al. 2002), it was used to compare such avirulent and virulent NIL at the transcriptome level. In the work reported here, several transcript-derived fragments (TDF) differential between avirulent and virulent $M$. incognita NIL of were isolated, and some clones of interest were investigated in more detail, in order to validate the cloning strategy described and to gain insight into their putative biological function.

\section{RESULTS}

\section{Isolation of differentially expressed genes.}

To analyze differential gene expression associated with nematode virulence or avirulence, cDNA-AFLP was carried out on infective second-stage juveniles (J2) from the two pairs of $M$. incognita avirulent and virulent NIL from Kursk and Morelos. The number and length, varying from about 100 to $800 \mathrm{bp}$, of the observed TDF were dependent on both the restriction enzymes and primer combination used (Fig. 1). In order to validate the initial steps of the experimental procedure, we looked for a TDF corresponding to the map- 1 gene, previously shown to be differentially expressed between the same NIL (Semblat et al. 2001). The primer combination $\mathrm{H}+\mathrm{G}$ and $\mathrm{M}+\mathrm{TG}$ was used, which should amplify a 820-bp fragment in the avirulent line from Morelos and should produce no amplification in the corresponding virulent NIL. In agreement with our previous results, the resulting cDNA-AFLP showed an amplification product at the expected size in the avirulent line (data not shown), indicating that the procedure worked correctly. Approximately 8,325, 7,700, and 8,000 bands per line were generated, using HindIII/MseI, PstI/MseI, and EcoRI/TaqI digestions, respectively. A very low proportion of these TDF proved to be differential, i.e., present in both avirulent NIL and absent in both virulent NIL (13, 4, and 5, respectively). Some examples of such TDF are presented in Figure 1. No differential TDF was found to be present in the virulent NIL and absent in the avirulent NIL. The 22 differential TDF were cloned and sequenced, and the hypothetical proteins deduced from the six-frame translated fragments were analyzed by BLASTX. The sequence similarities found are shown in Table 1. Fourteen of the TDF sequences did not show any significant similarity with known proteins, while eight matched reported sequences from nematodes (Caenorhabditis elegans and the plantparasitic species $M$. incognita and Heterodera glycines) and other invertebrates (the segmented tube worm Chaeopterus variopedatus and the insect Anopheles gambiae). For example, homologies were found with two proteases from $C$. elegans and $H$. glycines, cuticular precollagen from $M$. incognita, innexin (a gap-junction channel protein involved in intercellular communication) from $C$. variopedatus, or the unc-52 gene from $C$. elegans. Half of the 22 differential TDF showed homology to $M$. arenaria or $M$. incognita expressed sequence tags (EST), and five of the 14 sequences with no BLASTX homology did match to Meloidogyne EST, although no function has been described for them. Finally, nine TDF did not show significant matches to any known gene or EST sequence from databases. They may represent yet uncharacterized genes, but this result has to be considered carefully, since the DNA fragment lengths are rather short, which may limit the homology search analysis.

\section{Reverse transcription-polymerase chain reaction (RT-PCR) expression analysis.}

Transcription of the genes corresponding to the 22 differential TDF was analyzed by RT-PCR on mRNA from infective J2

Table 1. Summary of the 22 transcript-derived fragments (TDF) ${ }^{\mathrm{a}}$

\begin{tabular}{|c|c|c|c|c|c|c|c|}
\hline TDF name & Accession no. & $\begin{array}{l}\text { TDF/full-length } \\
\text { cDNA size (bp) }\end{array}$ & Highest homology & $\begin{array}{l}\text { BLASTX } \\
\text { E value }\end{array}$ & EST homology ${ }^{b}$ & $\begin{array}{c}\text { BLASTN } \\
\text { E value }\end{array}$ & RT-PCR $^{\mathbf{c}}$ \\
\hline HM1 & AJ544623 & $149 / 525$ & No homology & $\ldots$ & M. incognita $\mathrm{rd} 23 \mathrm{f} 01 . \mathrm{y} 1$ & e-138 & + \\
\hline HM2 & AJ544624 & 97 & Ribosomal protein Caenorhabditis elegans & $3 e-05$ & M. incognita rb06c09.y1 & $2 e-35$ & - \\
\hline HM3 & AJ544625 & 559 & Cuticle preprocollagen $M$. incognita & $1 \mathrm{e}-08$ & M. arenaria $\mathrm{rm} 39 \mathrm{~d} 10 . \mathrm{y} 1$ & 0.0 & - \\
\hline HM4 & AJ544626 & 169 & No homology & $\ldots$ & M. incognita rd15a10.y1 & $3 e-51$ & + \\
\hline HM5 & AJ544627 & 80 & No homology & $\ldots$ & $\ldots$ & $\ldots$ & - \\
\hline HM6 & AJ544628 & 274 & UNC-52 protein $C$. elegans & 5 e-20 & M. incognita rd08A06.y1 & $1 \mathrm{e}-122$ & - \\
\hline HM7 & AJ544629 & 205 & No homology & $\ldots$ & $\ldots$ & $\ldots$ & + \\
\hline HM8 & AJ544630 & 221 & Innexin Chaeopterus variopedatus & 5 e- 05 & $\ldots$ & $\ldots$ & - \\
\hline HM9 & AJ544631 & 650 & Aspartic protease $C$. elegans & $2 \mathrm{e}-27$ & $\ldots$ & $\ldots$ & - \\
\hline HM10 & AJ557572 & $394 / 1152$ & Cathepsin L-like Heterodera glycines & $1 \mathrm{e}-140$ & M. incognita ra23h02.y1 & 0.0 & - \\
\hline HM11 & AJ544633 & 300 & No homology & $\ldots$ & $\ldots$ & $\ldots$ & + \\
\hline HM12 & AJ544634 & $205 / 927$ & SacI homology domain C. elegans & 5 e-67 & $\ldots$ & $\ldots$ & + \\
\hline HM13 & AJ544635 & 204 & No homology & $\ldots$ & M.arenaria rm16h10.y1 & $1 \mathrm{e}-54$ & - \\
\hline PM1 & AJ544636 & $413 / 672$ & Hypothetical protein C. elegans & $2 \mathrm{e}-42$ & M. incognita $\mathrm{rd} 04 \mathrm{~g} 08 . \mathrm{y} 1$ & 0.0 & + \\
\hline PM2 & AJ544637 & 183 & No homology & $\ldots$ & $\ldots$ & $\ldots$ & + \\
\hline PM3 & AJ544638 & 201 & No homology & $\ldots$ & $\ldots$ & $\ldots$ & - \\
\hline PM4 & AJ544639 & 169 & No homology & $\ldots$ & $\ldots$ & $\ldots$ & + \\
\hline ET1 & AJ544640 & 321 & No homology & $\ldots$ & M. incognita ra03d09.y2 & 1 e-126 & - \\
\hline ET2 & AJ544641 & 319 & Hypothetical protein Anopheles gambiae & 9 e-21 & M. arenaria $\mathrm{rm} 39 \mathrm{c} 10 . \mathrm{y} 1$ & 5 e-76 & - \\
\hline ET3 & AJ544642 & 167 & No homology & $\ldots$ & $\ldots$ & $\ldots$ & + \\
\hline ET4 & AJ544643 & 223 & No homology & $\ldots$ & M. incognita MD0049 & 8 e-99 & - \\
\hline ET5 & AJ544644 & 167 & No homology & $\ldots$ & $\ldots$ & $\ldots$ & - \\
\hline
\end{tabular}

${ }^{a}$ Differential between Meloidogyne incognita avirulent and virulent near-isogenic lines (NIL).

${ }^{\mathrm{b}}$ TDF/full-length cDNA sequences were compared with available Meloidogyne spp. expressed sequence tags using BLASTN.

${ }^{c}+$ or - indicates a differential or nondifferential amplification pattern between the avirulent and virulent NIL. 
from the two pairs of $M$. incognita NIL. In these experiments, repeated at least twice for each TDF, nine genes showed the same pattern of amplification as that obtained in CDNA-AFLP experiments, i.e., presence of a band of the expected size in the two avirulent lines and absence in the two virulent lines (Table 1). An example of differential expression is shown in Figure 2. Conversely, 13 TDF presented comparable expression levels in both avirulent and virulent NIL (Table 1). Among the nine differentially expressed clones, three matched to $M$. incognita EST (HM1, HM4, and PM1), and one (PM1) to a C. elegans hypothetical protein. The six other TDF had no homology at all in the databases.

\section{In situ hybridization of selected TDF.}

In order to determine which nematode organs express the differential TDF, some of them were selected for further in situ hybridization experiments. Sense and antisense cDNA probes were made by asymmetric PCR and were used against $M$. incognita J2. Four TDF were selected, based on RT-PCR confirmation of their differential expression between avirulent and virulent NILS: HM7 and HM12 had no homology in databases, HM1 showed a significant match to a $M$. incognita EST sequence, and PM1 showed homology to a hypothetical protein from $C$. elegans and a $M$. incognita EST

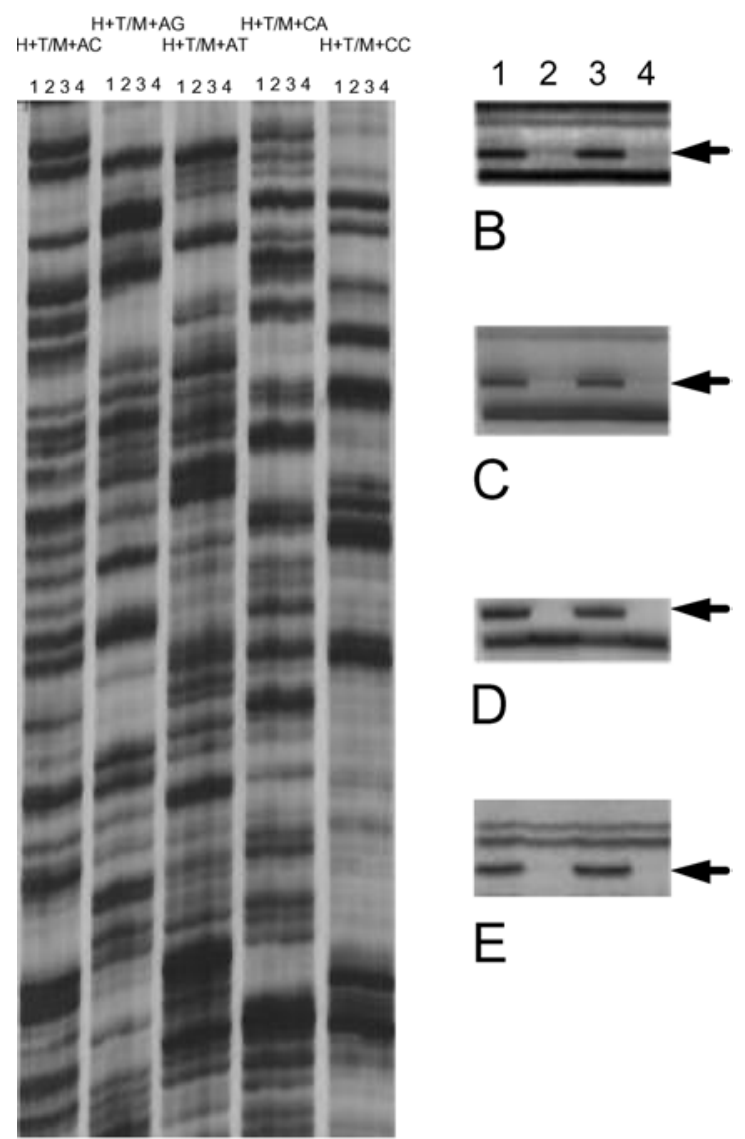

A

Fig. 1. Typical cDNA-amplification fragment length polymorphism patterns from Meloidogyne incognita near-isogenic lines (NIL) generated with $\mathrm{H}+1 / \mathrm{M}+2$ primer combinations. A, Conserved patterns generated with different primer combinations. B through $\mathbf{E}$, Selected parts of gels showing differential transcript-derived fragments: B, HM1, obtained with $\mathrm{H}+\mathrm{A} / \mathrm{M}+\mathrm{AC} ; \mathbf{C}, \mathrm{HM} 4$, obtained with H+T/M+GT; D, HM7, obtained with $\mathrm{H}+\mathrm{G} / \mathrm{M}+\mathrm{CC}$; and E, HM12, obtained with $\mathrm{H}+\mathrm{T} / \mathrm{M}+\mathrm{TG}$. 1, 2 and 3, $4=$ cDNA from avirulent and virulent NIL from Kursk and Morelos, respectively.
(Table 1). HM10 was homologous to a $H$. glycines cathepsin L-like protease (Table 1), a gene shown to be specifically transcribed in nematode intestinal cells (Gao et al. 2001), and was used as internal control. The in situ hybridization patterns are shown in Figure 3. Labeling was observed in the intestinal cells with the antisense probe of PM1. As expected, the same localization of expression was detected for HM10, used as control. Antisense probes of HM1 and HM7 specifically labeled the subventral esophageal glands and the dorsal esophageal gland of $\mathrm{J} 2$, respectively. Labeling of the dorsal gland ampulla was observed with the antisense probe of HM12 after $16 \mathrm{~h}$ of staining. When staining was extended to $72 \mathrm{~h}$, hybridization was detected in both the basal part and the ampulla of the dorsal gland, with a signal intensity higher in the ampulla. No labeling was detected for the control sense probes of all TDF (data not shown). The same results were obtained using independent batches of nematodes and newly synthesized hybridization probes.

\section{Full-length cDNA cloning} and predicted subcellular localization of mRNAs possibly encoding nematode-secreted proteins.

Since the presence of an N-terminal signal peptide may indicate that a protein is secreted and in order to get more sequence information, the sequence of the full-length cDNA was determined for the TDF previously localized in the intestinal (HM10 and PM1) or esophageal gland cells (HM1, HM7, and HM12). Only full-length sequences of HM1, HM10, HM12, and PM1 could be obtained. BLASTX sequence analysis confirmed that HM10 and PM1 encoded proteins with homology to a cathepsin L-like protease from $H$. glycines and a hypothetical protein from C. elegans, respectively. It also revealed that HM12 encoded a protein with homology to a SacI domain containing protein from $C$. elegans, the biological function of which may include the coordination of the activities of the secretory pathway. The computer algorithm SignalP (Nielsen et al. 1997) predicted the presence of a signal peptide for secretion for the proteins encoded by HM1 (in the subventral glands), HM10 (in the intestine), and HM12 (in the dorsal gland). Subcellular localization of the proteins encoded by HM1, HM10, HM12, and PM1 was evaluated using the PSORT II program (Nakai and Horton 1999). Proteins encoded by HM10 and HM12 were predicted to be extracellular, whereas the protein encoded by PM1 was predicted to be nuclear. For HM1, the prediction was less conclusive, the protein being possibly either cytoplasmic or within the vesicles of the secretory system.

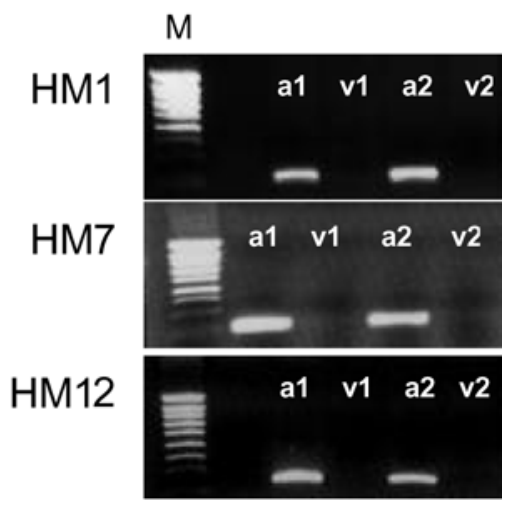

Fig. 2. Reverse transcription-polymerase chain reaction expression analysis of selected transcript-derived fragments. Equivalent amounts of cDNA from Meloidogyne incognita near-isogenic lines (NIL) were used (a1, v1 and a2, v2 = avirulent and virulent NIL from Kursk and Morelos, respectively). $\mathrm{M}=$ size molecular marker. 

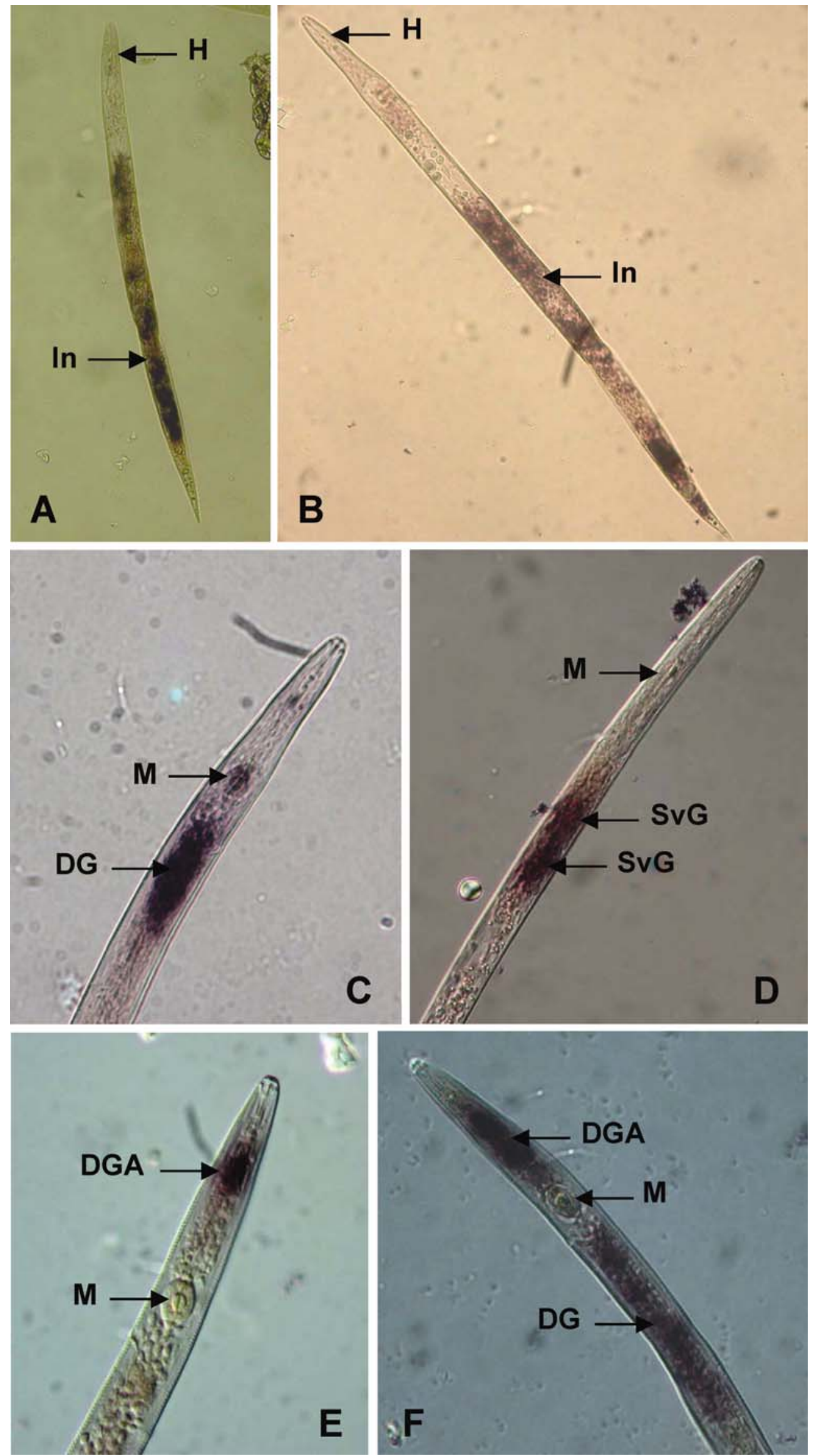

Fig. 3. In situ hybridizations with selected transcript-derived fragment antisense probes from Meloidogyne incognita. Labeling was done in avirulent infective J2s. Labeling patterns with A, HM10, B, PM1, C, HM7, D, HM1, E, HM12 (after one day of staining), and F, HM12 (after 3 days of staining) antisense probes. $\mathrm{DG}=$ dorsal gland; $\mathrm{DGA}=$ dorsal gland ampula; $\mathrm{H}=$ head; $\mathrm{I}=$ intestine; $\mathrm{M}=$ metacorpus; and $\mathrm{SvG}=$ subventral gland. 


\section{DISCUSSION}

In this paper, a comparative strategy based on cDNAAFLP analysis of NIL is described, which resulted in the identification of 22 genes differentially expressed between $M$. incognita lines avirulent or virulent against the tomato $M i$ resistance gene. Such differences between avirulent and virulent nematodes may indicate that some transcripts are missing in the virulent NIL but may also result from qualitative differences in mRNA sequence (mutations, deletions) between avirulent and virulent NIL. Clearly, further studies are needed to clarify that point. Based on sequence homology with known proteins, on localization of the transcripts in infective $\mathrm{J} 2$, or both, a putative function could be assigned to the products of some of these genes. Some other of these candidates were considered as pioneer sequences, but in both cases, the direct implication of these 22 sequences in nematode virulence or avirulence remains to be established. Since the NIL used in this study had been selected for 40 generations, a possible explanation would be that some of these differential bands are due to secondary effects or independent mutations not related to virulence or avirulence. An alternative explanation for the detection of genes polymorphic between avirulent and virulent lines and not related to the mechanism of virulence or avirulence is that such genes are located close to the avirulence genes on the chromosome and are lost together with the avirulence gene in case of a large deletion. However, two arguments suggest that they are not due to strong bias in the selection procedure. First, the fact that the same differences were found in two independent pairs of NILS tends to indicate that they are, indeed, correlated with the biological character of interest. Second, RTPCR analysis performed on RNA isolated from NIL of the same origin but selected for only 10 generations confirmed the differential patterns for a set of selected TDF (HM1, HM12, PM1, and PM2) (data not shown).

In our study, mRNA expression profiles from two pairs of M. incognita NIL from very different geographic origins were generated, using three restriction enzyme combinations, in order to maximize the coverage of the transcriptome of the nematode. Three six-cutter (EcoRI, HindIII, and PstI) and two four-cutter enzymes (MseI and $T a q \mathrm{I})$ were used, and MseI was associated with the six-cutter enzyme in two of the three combinations, as it cuts very frequently in most eukaryotic genomes (Vos et al. 1995). In each case, all the possible $(+1 /+2)$ primer combinations $\left(4 \times 4^{2}=64\right)$ were used and generated equivalent numbers of TDF, for a total of about 24,025. Sequencing of the $97-\mathrm{Mb}$ genome of the model nematode $C$. elegans predicted the occurrence of 19,099 protein-coding genes (The $C$. elegans Sequencing Consortium 1998), and recent data brought this number to 20,448 predicted proteins (McCarter et al. 2002). Considering the size of the $M$. incognita genome $(51 \mathrm{Mb})$ (Pableo and Triantaphyllou 1988), its expressed gene content, in the absence of other evidence, is expected to be in the same range as that of $C$. elegans (i.e., from 10,000 to 20,000 genes). In the closely related cyst nematode Globodera rostochiensis, the number of expressed genes in juveniles was estimated to be about 12,000 (Qin et al. 2000). Therefore, and taking into account the possible limitations inherent in the cDNA-AFLP methodology (redundancy of some TDF, under-representation of transcripts lacking a recognition site for the restriction enzymes used), it seems, nevertheless, reasonable to consider that the 24,025 TDF analyzed in this study represent a large fraction of the $M$. incognita transcriptome. Overall, a very low proportion of these TDF were shown to be differential (about $0.09 \%$ ), i.e., present in the two avirulent lines and absent in the two virulent lines. We never observed the opposite situation, i.e., a TDF present in the two virulent lines and absent in the two avirulent lines. Occasionally, other kinds of polymorphisms were observed (TDF present in the two lines from the same geographic origin and absent in the two others, TDF differential between the avirulent and virulent lines of a single origin only), but they were not taken into account in this study. If we consider that virulence or avirulence is due to several genes, then differences observed within a single pair of NIL may be of interest. Moreover, since our experiments were exclusively conducted on preparasitic $\mathrm{J} 2$, the possibility that the transcripts of some virulence or avirulence genes expressed later during parasitism have been missed must not be excluded.

In order to further characterize the differential TDF, we focused on some of those that proved to be differential in RTPCR experiments, although the lack of a differential RT-PCR amplification does not mean that the corresponding TDF are false differential clones (e.g., nucleotide polymorphism at the restriction enzyme recognition site). The PM1 clone, homologous to a $C$. elegans hypothetical protein, was shown to be specifically expressed in intestinal cells of $M$. incognita $\mathbf{J} 2$. The same expression pattern was detected for another TDF, HM10, homologous to a cathepsin L-like protease from H. glycines (Gao et al. 2001), which was not differential in RT-PCR but was used as a standard control in in situ hybridizations. Although the function of the genes corresponding to these two TDF remains to be determined, the fact that two independent putative intestinal proteins are found differential between avirulent and virulent NIL in cDNA-AFLP analysis suggests a possible link between food digestion by the nematode and its ability to develop or not on resistant plants. Interestingly, it has been shown in the parasitic nematode Haemonchus contortus and trematode Fasciola hepatica that gut-secreted cysteine proteases are not restricted to a digestive function in the intestine but are actively secreted from intestinal cells into the worm's external environment, where they interact with the extracellular matrix components of the host (Carnevale et al. 2001; Rhoads and Fetterer 1995). Further characterization of the full-length cDNA clones for HM10 and PM1 revealed the presence of a secretion signal peptide for HM10 only, which confirms that the encoded protein is putatively secreted. However, the presence or absence of a signal peptide is not a definitive argument, since some proteins lacking such a signal peptide have been shown to be secreted by potato cyst nematodes, Globodera spp. (Fioretti et al. 2001; Robertson et al. 2000).

Stylet secretions synthesized in the esophageal gland cells of root-knot nematodes are considered the main determinants of the pathogenicity of these organisms (Davis et al. 2000). Changes in esophageal gland activity during the parasitic cycle have been documented, i.e., active subventral glands in infective $\mathrm{J} 2$ and predominant activity of the dorsal gland in the later parasitic stages (Hussey and Mims 1990). Interestingly, the transcripts corresponding to three TDF were specifically localized to the subventral and the dorsal glands of J2. The in situ localization of HM1 mRNA in the subventral gland cells of $M$. incognita may indicate a role for the putative encoded protein in the early stages of interaction between the nematode and its host plant. However, its function remains unknown, since no homology was found in databases for this TDF. Localization of the transcripts corresponding to two other TDF, HM7 and HM12, was exclusively observed in the dorsal gland of the infective J2. This result suggests that the putative encoded proteins could be involved in later events of the parasitic cycle. In the case of HM12, mRNA concentrated into the region of the ampulla of 
the dorsal gland. In $M$. incognita, secretory proteins are produced in the nuclear region of the gland cell and stored into spherical granules that are transported to the cell ampulla before their excretion into the esophagus lumen by exocytosis. In parasitic $\mathbf{J} 2$, the dorsal gland ampulla is enlarged and contains many secretory granules (Hussey and Mims 1990). Our observation that HM12 transcripts are preferentially located in the region of the dorsal gland ampulla of infective preparasitic $\mathrm{J} 2$ may indicate a possible role of the gene in both early and late parasitic interactions with the plant. No homology in databases was found for HM7 and HM12, and thus, their precise implication in nematode parasitism has not been resolved. Characterization of the full-length cDNA clones for HM1 and HM12 revealed the presence of an N-terminal signal peptide, which confirms the putative secretion of these proteins from the subventral and dorsal glands, respectively. However, functional analyses will have to be performed to demonstrate the implication of these genes in $M$. incognita virulence or avirulence against the $M i$ gene. In that respect, the RNAi procedure, shown to be efficient for cyst nematodes (Urwin et al. 2002), would be of interest in our model system. Indeed, changes in the (resistant) plant-nematode interaction phenotype after inactivation of the candidate genes identified here would be strong arguments in favor of their role in $M$. incognita virulence or avirulence.

The strategy developed here to identify genes differentially expressed between avirulent and virulent root-knot nematodes did not require any a priori knowledge about the functions to be involved. However, it resulted in the characterization of a set of genes putatively coding for esophageal gland secretions, which are thought to be among the main $M$. incognita pathogenicity factors (Davis et al. 2000; Huang et al. 2003; Jaubert et al. 2002). This observation could suggest a possible dual role for such secretions and is in line with current accumulating evidence that most avirulence genes found in biotrophic pathogens are or once were pathogenicity genes that encode protein signals that trigger transduction pathways into plant cells (Gabriel 1999; White et al. 2000).

\section{MATERIALS AND METHODS}

\section{Nematodes.}

Two $M$. incognita isolates from very different geographic origins (Kursk, Russia and Morelos, Mexico, respectively), both avirulent against the tomato $M i$ resistance gene, were used. They were multiplied on the susceptible tomato cv. Saint Pierre. From each avirulent isolate, a NIL was selected for virulence on the $M i$-resistant tomato cv. Piersol, according to the procedure originally described by Jarquin-Barberena and associates (1991). In this study, we used avirulent and virulent NIL that were selected on Saint Pierre and Piersol, respectively, for 40 successive generations.

Eggs were collected after treatment of the egg masses in $0.5 \% \mathrm{NaOCl}$ and were rinsed with distilled water. $\mathrm{J} 2$ were then hatched in vitro on $10-\mu \mathrm{m}$ sieves in $0.7 \%$ streptomycin sulphate and were directly used for in situ hybridization experiments or were concentrated by centrifugation and were stored at $-80^{\circ} \mathrm{C}$ until RNA extraction.

\section{RNA isolation.}

For each nematode line, total RNA was isolated from $200 \mu \mathrm{l}$ of J2 with TRIzol Reagent (Invitrogen, Cergy-Pontoise, France), following the manufacturer's instructions, after a preliminary step of grinding in liquid nitrogen. Subsequently, mRNA was purified from total RNA with the MicroPoly(A)Purist kit (Ambion, Huntingdon, U.K.), according to the manufacturer's recommendations.
cDNA-AFLP procedure.

The two pairs of avirulent and virulent $M$. incognita NIL were compared with cDNA-AFLP derived markers. cDNAAFLP was performed as described by Bachem and associates (1996) with minor modifications. First-strand cDNA was synthesized from $1 \mu \mathrm{g}$ of mRNA with a $\mathrm{T}_{16} \mathrm{VN}$ oligonucleotide primer ( $\mathrm{V}=\mathrm{A}, \mathrm{C}$, or $\mathrm{G} ; \mathrm{N}=\mathrm{A}, \mathrm{T}, \mathrm{C}$, or $\mathrm{G})$. Double-stranded cDNA synthesis was performed with the Superscript doublestranded cDNA synthesis kit (Invitrogen, Cergy-Pontoise, France). Each cDNA sample was digested by two restriction endonucleases, and three pairs of restriction endonucleases were successively tested: HindIII/MseI, PstI/MseI, and EcoRI/TaqI. After digestion, the restriction fragments were ligated with their corresponding adapters (Semblat et al. 2000; Thomas et al. 1995; Vos et al. 1995), and preamplification was carried out for 25 cycles $\left(94^{\circ} \mathrm{C}, 30 \mathrm{~s} ; 57^{\circ} \mathrm{C}, 45 \mathrm{~s} ; 72^{\circ} \mathrm{C}, 60 \mathrm{~s}\right)$, using primers without selective nucleotide (E+0: $5^{\prime}$-GTAGAC TGCGTACCAATTC-3', H+0: 5'-GACTGCGTACCAGCTT3', P+0: 5'-GACTGCGTACCAGTGCAG-3', M+0: 5'-GATGA GTCCTGAGTAA-3', and T+0: 5'-GATGAGTCCTGAGCGA$\left.3^{\prime}\right)$. The PCR products were diluted $(10 \times)$ in Tris-EDTA (TE) buffer, and $2 \mu \mathrm{l}$ were used for selective amplification, with one selective base extension at the 3' end of the primers $\mathrm{H}+0, \mathrm{E}+0$, and $\mathrm{P}+0$ and two selective base extensions at the $3^{\prime}$ end of the primers $\mathrm{M}+0$ and $\mathrm{T}+0$, using a standard AFLP touchdownselective amplification program. All the possible primer combinations $\left(4 \times 4^{2}=64\right)$ for each pair of restriction endonucleases were tested in these experiments. The PCR products were electrophoresed in $4.5 \%$ denaturing polyacrylamide gels. The gels were dried on 3MM paper (Whatman, Maidstone, U.K.) under vacuum and were exposed to Kodak Biomax film (Amersham, Buckinghamshire, England) at room temperature for $24 \mathrm{~h}$.

\section{TDF analysis and sequencing.}

Because more than one DNA fragment can be present in a single band, purification of the differential TDF was performed as follows. Bands of interest (i.e., those that were present in the two avirulent and absent in the two virulent NIL) were cut from the dried polyacrylamide gel and were soaked in $25 \mu \mathrm{l}$ of TE buffer. The same procedure was applied to the corresponding regions of the same size in the virulent NIL lanes in which no band was present. DNA was recovered after three cycles of "freeze and thaw" in liquid nitrogen. Diffusate $(2 \mu \mathrm{l})$ from avirulent and virulent NIL were reamplified, using new selective primer combinations with one additional nucleotide in the primers corresponding to the six-cutter enzyme adaptor $(+2 /+2$ instead of $+1 /+2$ in the initial cDNA-AFLP step), and only TDF displaying the same differential expression pattern as that exhibited in the cDNA-AFLP gel were analyzed further. They were cloned into pGEM-T easy vector (Promega, Charbonnières, France) and sequenced by Genome Express (Grenoble, France). Database searches were performed using the BLAST Network Service (National Center for Biotechnology Information). Each TDF sequence was compared against all sequences in the nonredundant databases, using the BLASTX algorithm (Altschul et al. 1997). In addition, TDF sequences were also compared against the EST databases using the BLASTN algorithm.

In order to get full-length sequence information, $5^{\prime}$ and $3^{\prime}$ ends of some TDF of interest were isolated by RNA ligase-mediated rapid amplification of cDNA ends, using the GeneRacer Kit (Invitrogen) according to the manufacturer's instructions. Bioinformatic analysis of the obtained sequences was performed as described previously. Moreover, the amino acid sequence of each predicted protein was analyzed for the presence 
of an N-terminal secretion signal peptide, using the program SignalP (Nielsen et al. 1997), and its putative subcellular localization was predicted using PSORT analysis (Nakai and Horton 1999).

\section{RT-PCR amplification.}

RT-PCR experiments were performed using oligonucleotide primers that were designed from each TDF sequence of interest. For each nematode avirulent and virulent NIL, first-strand cDNA was synthesized from $200 \mathrm{ng}$ of mRNA, using a $\mathrm{T}_{16} \mathrm{VN}$ oligonucleotide primer $(\mathrm{V}=\mathrm{A}, \mathrm{C}$, or $\mathrm{G} ; \mathrm{N}=\mathrm{A}, \mathrm{T}, \mathrm{C}$, or $\mathrm{G})$ and the Superscript II reverse transcriptase (Invitrogen) in a reaction volume of $20 \mu \mathrm{l}$. PCR reactions were performed using $2 \mu \mathrm{l}$ of the first-strand reaction volume as template, $1 \mathrm{U}$ of Taq polymerase (Appligene Oncor, Illkirch, France), and $0.25 \mathrm{mM}$ dNTPs, each, and primers $(0.3 \mu \mathrm{M}$ each $)$ for $3 \mathrm{~min}$ at $94^{\circ} \mathrm{C}, 30$ cycles at $94^{\circ} \mathrm{C}$ for $45 \mathrm{~s}, 57^{\circ} \mathrm{C}$ for $45 \mathrm{~s}, 72^{\circ} \mathrm{C}$ for $60 \mathrm{~s}$, and a final elongation of $5 \mathrm{~min}$ at $72^{\circ} \mathrm{C}$.

\section{In situ hybridization.}

For in situ hybridization, specific primers designed from the cloned TDF of interest were used to amplify the cDNAs in the plasmids. These PCR products were then used to synthesize digoxigenin-labeled sense and antisense cDNA probes by asymmetric PCR. In situ hybridizations were performed on $\mathrm{J} 2$ from avirulent NIL essentially as described previously (De Boer et al. 1998). Briefly, freshly hatched J2 were fixed in $2 \%$ paraformaldehyde for $16 \mathrm{~h}$ at $4^{\circ} \mathrm{C}$ and $4 \mathrm{~h}$ at room temperature. Nematodes were permeabilized with proteinase $\mathrm{K}$, acetone, and methanol. They were then hybridized at $45^{\circ} \mathrm{C}$ with the sense and antisense single-strand cDNA probes for $16 \mathrm{~h}$. Bound cDNA probes were detected by alkaline phosphatase immunostaining at $4{ }^{\circ} \mathrm{C}$ for $16 \mathrm{~h}$. The stained $\mathrm{J} 2$ were then examined with differential interference microscopy.

\section{ACKNOWLEDGMENTS}

This research was supported by the European Community grant QLK5-1999-01462.

\section{LITERATURE CITED}

Altschul, S. F., Madden, T. L., Schaffer, A. A., Zhang, J. H., Zhang, Z., Miller, W., and Lipman, D. J. 1997. Gapped BLAST and PSI-BLAST: A new generation of protein database search programs. Nucleic Acids Res. 25:3389-342.

Bachem, C. W. B., Van der Hoeven, R. S., De Bruijn, S. M., Vreugdenhil, D., Zabeau, M., and Visser, R. G. 1996. Visualization of differential gene expression using a novel method of RNA fingerprinting based on AFLP: Analysis of gene expression during potato tuber development. Plant J. 9:745-753

Bost, S. C., and Triantaphyllou, A. C. 1982. Genetic basis of the epidemiologic effects of resistance to Meloidogyne incognita in the tomato cultivar Small Fry. J. Nematol. 14:540-544.

Carnevale, S., Rodriguez, M. I., Guarnera, E. A., Carmona, C., Tanos, T., and Angel, S. O. 2001. Immunodiagnosis of fasciolosis using recombinant procathepsin L cystein proteinase. Diagn. Microbiol. Infect. Dis. 41:43-49.

The C. elegans Sequencing Consortium. 1998. Genome sequence of the nematode $C$. elegans: A platform for investigating biology. Science 282:2012-2018.

Davis, E. L., Hussey, R. S., Baum, T. J., Bakker, J., Schots, A., Rosso, M N., and Abad, P. 2000. Nematode parasitism genes. Annu. Rev. Phytopathol. 38:365-396.

De Boer, J. M., Yant, Y., Smant, G., Davis, E. L., and Baum, T. J. 1998. In situ hybridization to messenger RNA in Heterodera glycines. J. Nematol. 30:309-312.

Durrant, W. E., Rowland, O., Piedras, P., Hammond-Kosack, K. E., and Jones, J. D. G. 2000. cDNA-AFLP reveals a striking overlap in racespecific resistance and wound response gene expression profiles. Plant Cell 12:963-977.
Eddaoudi, M., Ammati, M., and Rammah, H. 1997. Identification of resistance breaking populations of Meloidogyne on tomatoes in Morocco and their effect on new sources of resistance. Fund. Appl. Nematol. 20:285-289.

Fioretti, L., Warry, A., Porter, A., Haydock, P., and Curtis, R. 2001. Isolation and localisation of an annexin gene ( $g p-n e x)$ from the potato cyst nematode Globodera rostochiensis. Nematology 3:45-54.

Gabriel, D. W. 1999. Why do pathogens carry avirulence genes? Physiol. Mol. Plant Pathol. 55:205-214.

Gao, B., Allen, R., Maier, T., Davis, E. L., Baum, T. J., and Hussey, R. S. 2001. Identification of putative parasitism genes expressed in the esophageal gland cells of the soybean cyst nematode Heterodera glycines. Mol. Plant-Microbe Interact. 14:1247-1254.

Huang, G., Gao, B., Maier, T., Allen, R., Davis, E. L., Baum, T. J., and Hussey, R. S. 2003. A profile of putative parasitism genes expressed in the esophageal gland cells of the root-knot nematode Meloidogyne incognita. Mol. Plant-Microbe Interact. 16:376-381.

Hussey, R. S., and Mims, C. W. 1990. Ultrastructure of esophageal glands and their secretory granules in the root-knot nematode Meloidogyne incognita. Protoplasma 156:9-18.

Jarquin-Barberena, H., Dalmasso, A., De Guiran, G., and Cardin, M. C. 1991. Acquired virulence in the plant parasitic nematode Meloidogyne incognita. I. Biological analysis of the phenomenon. Rev. Nématol. 14:299-303.

Jaubert, S., Ledger, T. N., Laffaire, J. B., Piotte, C., Abad, P., and Rosso, M. N. 2002. Direct identification of stylet secreted proteins from rootknot nematodes by a proteomic approach. Mol. Biochem. Parasitol. 121:205-211.

McCarter, J. P., Clifton, S. W., McK Bird, D., and Waterston, R. H. 2002. Nematode gene sequences, update for June 2002. J. Nematol. 34:71-74.

Milligan, S., Bodeau, J., Yaghoobi, J., Kaloshian, I., Zabel, P., and Williamson, V. M. 1998. The root-knot nematode resistance gene Mi from tomato is a member of the leucine zipper, nucleotide binding, leucine-rich repeat family of plant genes. Plant Cell 10:1307-1319.

Nakai, K., and Horton, P. 1999. PSORT: A program for detecting sorting signals in proteins and predicting their subcellular localization. Trends Biochem. Sci. 24:34-35.

Nielsen, H. Engelbrecht, J., Brunak, S., and Von Heijne, G. 1997. Identification of prokaryotic and eukaryotic signal peptides abd prediction of their cleavage sites. Protein Eng. 10:1-6.

Ornat, C., Verdejo-Lucas S., and Sorribas, F. J. 2001. A population of Meloidogyne javanica from Spain virulent to the $M i$ resistance gene in tomato. Plant Dis. 85:271-276.

Pableo, E. C., and Triantaphyllou, A. C. 1988. DNA complexity of the root-knot nematode (Meloidogyne spp.) genome. J. Nematol. 21:260-263.

Qin, L., Overmars, H., Helder, J., Popeijus, H., van der Voort, J. R., Groenink, W., van Koert, P., Schots, A., Bakker, J., and Smant, G. 2000. An efficient cDNA-AFLP-based strategy for the identification of putative pathogenicity factors from the potato cyst nematode Globodera rostochiensis. Mol. Plant-Microbe Interact. 13:830-836.

Rhoads, M. L., and Fetterer, R. H. 1995. Developmentally regulated secretion of cathepsin L-like cysteine proteases by Haemonchus contortus. J. Parasitol. 81:505-512.

Roberts, P. A. 1995. Conceptual and practical aspects of variability in root-knot nematodes related to host plant resistance. Annu. Rev. Phytopathol. 33:199-221.

Robertson, L., Robertson, W. M., Sobszak, M., Helder, J., Tetaud, E., Arivanayagam, M. R., Ferguson, M. A., Fairlamb, A., and Jones, J. T. 2000. Cloning, expression and functional characterisation of a peroxiredoxin from the potato cystnematode Globodera rostochiensis. Mol. Biochem. Parasitol.111:41-49.

Semblat, J. P., Bongiovanni, M., Wajnberg, E., Dalmasso, A., Abad, P., and Castagnone-Sereno, P. 2000. Virulence and molecular diversity of parthenogenetic root-knot nematodes, Meloidogyne spp. Heredity 84:81-89.

Semblat, J. P., Rosso, M. N., Hussey, R. S., Abad, P., and CastagnoneSereno, P. 2001. Molecular cloning of a cDNA encoding an amphidsecreted putative avirulence protein from the root-knot nematode Meloidogyne incognita. Mol. Plant-Microbe Interact. 14:72-79.

Simoes-Araujo, J. L., Rodrigues, R. L., Gerhardt, L. B. de A., Mondego, J. M. C., Alves-Ferreira M., Gouvea Rumjanek N., and MargisPinheiro, M. 2002. Identification of differentially expressed genes by cDNA-AFLP technique during heat stress in cowpea nodules. FEBS (Fed. Eur. Biochem. Soc.) Lett. 515:44-50.

Smith, P. G. 1944. Embryo culture of a tomato species hybrid. Proc. Am Soc. Hortic. Sci. 44:413-416.

Thomas, C. M., Vos, P., Zabeau, M., Jones, D. A., Norcott, K. A., Chadwick, B. P., and Jones, J. D. G. 1995. Identification of amplified restriction fragment polymorphism (AFLP) markers tightly linked to 
the tomato $C f-9$ gene for resistance to Cladosporium fulvum. Plant $\mathbf{J}$. 8:785-794.

Triantaphyllou, A. C. 1985. Cytogenetics, cytotaxonomy and phylogeny of root-knot nematodes. Pages 113-126 in: An Advanced Treatise on Meloidogyne. Vol. 1. J. N. Sasser, and C. C. Carter, eds. North Carolina State University Graphics, Raleigh, NC, U.S.A.

Trudgill, D. L. 1991. Resistance to and tolerance of plant parasitic nematodes in plants. Annu. Rev. Phytopathol. 29:167-192.

Urwin, P. E., Lilley, C. J., and Atkinson, H. J. 2002. Ingestion of doublestranded RNA by preparasitic juvenile cyst nematodes leads to RNA interference. Mol. Plant-Microbe Interact. 15:747-752.
Vos, P., Hogers, R., Bleeker, M., Reijans, M., van de, L. T., Hornes, M., Frijters, A., Pot, J., Peleman, J., Kuiper, M., and Zabeau, M. 1995. AFLP: A new technique for DNA fingerprinting. Nucleic Acids Res. 23:4407-4414.

White, F. F., Yang, B., and Johnson, J. B. 2000. Prospects for understanding avirulence gene function. Curr. Opin. Plant Biol. 3:291-298.

Williamson, V. M. 1998. Root-knot nematode resistance genes in tomato and their potential for future use. Annu. Rev. Phytopathol. 36: 277-293.

Williamson, V. M., and Hussey, R. S. 1996. Nematode pathogenesis and resistance in plants. Plant Cell 8:1735-1745. 